\title{
Improving English Reading and Spelling by Intact Learners and Learners with Dyslexia in English Language Classrooms
}

\author{
Daniela Soradova \\ Constantine the Philosopher University in \\ Nitra, Slovakia
}

\author{
Zdena Kralova \\ Constantine the Philosopher University in \\ Nitra, Slovakia
}

\begin{abstract}
The paper presents pilot research results of the questionnaire and action research focusing on teaching intact and dyslexic young learners English reading/pronunciation and spelling. The results of the questionnaire showed us what methods for teaching English reading and spelling teachers prefer to use and whether they know the Phonics method. The Phonics is supposed to be the most common method used for teaching English reading and spelling in the native environment. As the Phonics method is not very common in Slovak environment, we have decided to apply the Phonics generalizations at the lessons of English as a foreign language and find out whether it is beneficial for improving learners' reading, pronunciation and spelling skills.
\end{abstract}

\section{Introduction}

Teaching and learning how to read and write is a struggle in each language. It can be even much more challenging and time-consuming when the language is non-phonemic, as English for instance. When Slovak learners start to learn how to read and write in English, they consider English difficult as compared to the Slovak language. In English there are more sounds than letters and their combinations creating different words sometimes cause problems for reading and spelling. However, we have realized that the Phonics instructions can bring more logic into English reading and spelling, and therefore, the Phonics could be introduced at the lessons of English as a foreign language. Although Phonics approach gives basis for many other accommodated methods on teaching learners how to read and write, the logic of the approach is present in each one. What is more, its cumulative, structured and multisensory characteristics make it suitable for teaching learners with special educational needs such as dyslexia or dysgraphia. In the following lines we are going to present partial results of the pilot research focusing on the Phonics method in teaching English spelling, reading and pronunciation to non-native intact learners alongside inclusive learners.

\section{Dyslexia as a learning difference}

It is very hard to understand thoroughly how our brain processes the world around, mainly when it defies all logic or the mainstream processing. Brain of a dyslexic learner is one of the examples. On the one hand, there is no brain damage or a significant sign that warns us straightway that a learner is dyslexic. There are, on the other hand, little notices that try to catch our attention in order to point out the difference. Referring to naming "Learners with Special Educational Needs" or "Learners with Learning Differences" there is just need to implement different approaches into learning and teaching.

Although dyslexia influences mainly literacy, dyslexic learners can also have problems to remember spoken information properly and retrieve words from a long term memory. Dyslexia is dimensional and symptoms of dyslexia range from mild to severe. Dyslexia may also be accompanied by attention deficit or autistic syndromes. We need to keep in mind that each individual is unique and symptoms of dyslexia vary from learner to learner in their intensity and severity [1].

Some learners may have minor difficulties, while others may even suffer from other developmental disorders such as ADD or ADHD, dyscalculia or dyspraxia. Glue ear (lat. Ottis Media) is also common among learners with dyslexia and it affects the acquisition of auditory discrimination skills, which later influence development of reading. The Asperger's syndrome or immune system disorders such as asthma or eczema may occur as well [2]. As dyslexia rarely appears in isolation and the signs are miscellaneous, the right diagnosis is the first and the foremost step that requires patience and the cooperation of teachers, special educators and psychologists.

Learners with special educational needs are not ill, so even after the diagnosis, there is no cure to fix the problem and wait until it works. From this point on, different methods, techniques and learning styles need to be tried and new ways and accommodations need to be introduced in order to make school years of 
dyslexic learners or learners with other special needs productive and enjoyable.

There are three common levels how a learner can be integrated back to learning process:

Integration: Integration suggests the adaptation of a student to school, where extra adaptations or services would be offered to help a learner fit into classroom, to integrate them, rather than for a mainstream school to transform its own practices [3].

Inclusive education: Inclusive approach assumes that differences among individual learners are normal and it is the educational system that needs to be adapted to learners' needs. Inclusion rejects separating learners with SpLDs from intact learners. It is believed, that by providing certain alternations, learners with SpLDs can be successfully integrated into educational system, although learners like these may require less or more individualized instructions depending on the severity of SpLD to overcome their learning problems [3].

Accommodations: Accommodations are solutions and arrangements offered to learners with SpLD to respond to their special needs and to enable them to show their potential and perform to prove their knowledge and complete the assignments as other learners despite difficulties they encounter. Accommodations should not change the expectations for learner's performance or be unfair compared to intact learners. Basically, the outcome should be the same by both intact learners and those with SpLDs, but the process of getting to the outcome is accommodated to the learners with SpLDs [3].

As the naming implies, these learners need just a different approach in order to manage school as good as mainstream students. Therefore, the accommodations or different methods ought to be tried. What is more, new methods or accommodations would not slow the mainstream learners down, they would only help those learners, who do not follow the classical approach.

\subsection{Dyslexia and learning a foreign language}

It is assumed, that if a learner is diagnosed with dyslexia in their native language, the effects of dyslexia are going to be the same or very similar, depending on the structure of the language, also in a foreign language. The vast majority of dyslexic pupils exhibit mainly phonological difficulties and are likely to have problems with a new language [4]. Moreover, auditory discrimination often makes it much harder and the time they need for processing the language is also a crucial factor. Dyslexic pupils speak more slowly in a foreign language and their working and short-term memory difficulties make it likely that learning vocabulary will pose problems as well. It is said, that pupils who have even mild difficulties in learning to read, write and master phonology of their native language, may find it difficult to learn a foreign language, but they will probably reach a reasonable standard if the try hard [4].

Dyslexic learners have very weak phonemic awareness, that is, they have problems to recognize words automatically or fast enough to allow comprehension. They struggle with blending and segmenting words into sounds or even rhyme words and therefore, they need different and specialized instructions to master the alphabetic code [5]. However, to gain even the reasonable standard they need great help from the teacher. The teacher's challenge is thus to find the most effective methods for pupils with special educational needs.

\subsection{Requirements of dyslexic learners}

Due to poor memory and weak phonemic awareness, dyslexic learners need as many opportunities for revision as possible alongside ample practice engaging all the senses in order to provide sufficient and long-lasting fixation into long-term memory.

A number of authors suggest using the Multisensory Structured Language (MSL) approach based on the work of Gillingham and Stillman, who explain: "Grammar, syntax and language phonology require to be taught through a programme that emphasises hearing, seeing, speaking and writing the language. A major challenge to teachers is to determine how these methods can be employed in busy modern language classrooms. One answer is to use the techniques with a whole group of pupils so that in the addition to the direct teaching being given, students can also practise among themselves to give the over-learning necessary for retention. Methods should explicitly teach correspondence between written aspects and the sounds they make [5]."

A younger approach based on MSL is the OrtonGillingham Approach giving learners explicit and direct teaching in sound-letter correspondence activating different sensory channels at the same time. This approach has created different hints that help learners to remember how to write confusing letter like $b$ and $d$ by different strokes, for example, students make the vertical line before drawing the circle in printing the letter $b$; they form the circle before drawing the vertical line in printing the letter $\mathrm{d}$ [6].

In other words, there is need to develop phonological and orthographic awareness, that is, recognize and identify syllables, onsets, rimes and individual sounds, differentiate sounds, divide words into syllables and sounds, remove or reposition the sounds to form new words. This can be ensured by various multi-sensory techniques such as picture cards, flash cards, tokens, letter cards, graphic models, word slides, bingos, dominoes, etc.

Furthermore, other accommodations like customizing the font, enlarging the font if necessary, 
generally adjusting reading materials according to dyslexic needs contribute to better learning environment. However, as learners' symptoms vary from mild to severe, the accommodations of their educational needs vary as well and highly individualized approach is required.

To sum it up, we understand, that it is not possible to teach only one skill at the time and that all the skills influence each other. Therefore, the strategies we use for teaching pronunciation, spelling and reading should:

- $\quad$ adopt metacognitive skills,

- train memory,

- motivate and use motivating materials and technology,

- train auditory discrimination,

- $\quad$ serve as a model [4].

There are more strategies that are likely to help pupils with learning differences. As each pupil is unique, the teacher has to be able to accommodate the strategies and methods to their needs.

\section{Phonics}

Learning reading is the first step to education. Without reading we would be restricted in knowledge and our communication skills would be much poorer. However, this first step is in each language timeconsuming and demanding and each language has its peculiarities and own system how to teach children to read. Languages that are phonemic, i.e. there is a complete one-to-one correspondence between graphemes (printed symbols) and phonemes (speech sounds), tend to be learnt easier as each letter represents one sound. A language like this is Slovak, for instance. On the other hand, English is highly nonphonemic. Although English language is alphabetic as Slovak, there is no straightforward relationship between graphemes and their phonemic realization. Often, one letter is pronounced in different ways or a group of letters form one sound, or even one sound can be represented by different letters. In order to learn these patterns, they must be put into a logical order. And this is what Phonics does.

Phonics is an approach based on the letters and sounds, where pupils are taught the letters of the alphabet and the combinations of letter phonically [7]. As a single letter or a combination of letters in the English alphabet might be pronounced in many different ways or one sound may be represented by different letters, Phonics explain the association of phonemes and graphemes [8] and makes reading and spelling logical.

However, learners need to be ready for Phonics. This preparatory period named by Burns, Roe and Ross "readiness for reading" lasts since a child's birth and is seen in its range of vocabulary, the way they enunciate words, the ability to interpret pictures and following directions and perceiving small sight and sound differences [8]. Recent research has shown, that the ability to hear sounds within a word when it is spoken is the critical first step in learning how to read. In other words, phonemic awareness, is an auditory skill which enables learners differentiate between individual sounds. We may consider phonemic awareness to be a precursor and an important pre-skill to Phonics as children need to be able to recognize individual sounds in order to work with Phonics.

There are different opinions on which sounds should be presented first. Some teachers prefer introducing vowels first as each word contains a vowel sound. However, they are not sure, either long or short vowels should come first [8]. On the contrary, there are many programmes that start with consonant sounds and introduce vowels later, because consonants are more consistent, usually present one sound and can be identified more easily within a word. Although, it varies from a programme to programme, they all agree that good Phonics instructions are essential, so that children internalize the process of word identification.

According to how Phonics is introduced, we divide it into Synthetic and Analytical Phonics. On the one hand, Analytic Phonics focuses on the whole word primarily and later analyses individual components of the word. Pupils analyse letter-sound relation after getting familiar with the word avoiding pronouncing sounds in isolation to guess the word. On the other hand, Synthetic Phonics pays attention to individual sounds associated with letters or letter combinations and then blends the sound together in order to pronounce the word. It is also known as a part-towhole approach as opposed to Analytical approach which is whole-to-part.

There has been a disagreement on which approach is more suitable for beginning either native or even non-native learners. Defenders of either one proposes their advantages.

To sum it up, Analytical Phonics or Whole Word Approach almost identical with Whole Language Approach a.k.a. Top Down Approach exposes children to the whole text letting them take the meaning from language contextually without focusing on a structure and decoding [9]. However, learners exposed just to Analytical Approach find it more difficult to decode individual words and read them properly and struggle with everyday writing. [10].

On the one hand, in makes sense, that we read to understand what we are reading about, but on the other hand, not being able to read words correctly, mostly leads to wrong remembering of the pronunciation of the word and takes some time and effort to correct the error or if not eliminated, it may cause later problems in speech [11]. Even the argument that English is irregular, is no longer valid, as Synthetic Phonics presents regularities in English, 
although not as in Slovak language, but as Bowey pointed out, 80\% of English is regular [12].

It may sound, that there is no agreement on which type of the Phonics Approach is more effective. To sum it up, Phonics as an approach from which many other programmes such as "Linguistic Phonics", "Systematic Contextual Phonics", "Embedded Phonics", "Jolly Phonics" and many more emerged. The programmes are either synthetically-centred or analytically-centred depending on whether their procedure is whole-to part or part-to-whole. Some of them focus on first-language learners, some of them are more appropriate for second-language learners. What is more, different programmes are based on different local dialects depending on the area, so the sounds may vary. There has been so much confusion over the years and thus, one must always look beyond the title of the reading programme.

Hiskes explains that there is so much confusion, because for more than 40 years teachers have been without phonics texts or even courses in teacher's colleges. Almost everyone would agree that "reading for meaning" should be the primary objective of any method. However, could be that achieved without proper decoding? Hiskes further explains, that students need to be able to effortlessly decode their comprehension vocabulary and then they are free to "read for meaning" instead of struggling while "meaning to read". After mechanics of sound-to-word has been mastered, the focus can be fully put on meaning [11].

\subsection{Phonics and dyslexia}

Based on the requirements of dyslexic learners and the characteristics of the Phonics method (structured, cumulative and multisensory), Phonics is supposed to work by dyslexic learners. A lot of research has been devoted to studying effects of Phonics instructions on dyslexic learners. Mainly, the research has been carried out in English speaking countries with English speaking dyslexic learners. Basically, the studies proved the positive effect of the Phonics instructions on teaching English reading and spelling to dyslexic learners and suggest teaching Phonics for them [11].

As dyslexia is becoming more and more discussed, parents, teachers and laymen can find lots of information about how to teach dyslexic learners using Phonics. Government of the United Kingdom has provided publication that focuses on early reading, including systematic Phonics, literacy and inspection methodology. It is an online distance learning training module for teachers and inspectors from The Office Standards in Education to support the inspection of literacy in schools. Further, the British Dyslexia Association suggests Phonics for teaching English reading and spelling as it is structured, cumulative and multisensory. It likewise explains that dyslexic learners do not pick literacy skills easily and thus, they have to be taught deliberately, in one-to-one or very small groups [13].

In 2015, McArthur et al. carried out a study, in which they compared the Phonics Training and the Sight-Word Training in children with dyslexia and tried to determine if different orders of the Phonics Training and the Sight-Word Training have different effects on reading skills of dyslexic children. The Phonics Training means teaching Phonics rules and applying them while reading. The Sight-Word Training, which is similar to the Look and Say Method, means learning a group of words by heart as one third of English words is irregular, so the Phonics rules are not applicable. After the 16-week intervention, the outcomes of the study showed, that the Sight-Word Training had a significant effect in reading trained and untrained irregular words. This effect was higher in case of the Sight-Word Training compared to the Phonics Training with trained irregular words. It indicates that the Phonics knowledge can help children learn irregular words, as the Phonics rules allow learners to guess the whole word. On the other hand, the Phonics Training had significant effect on the non-word reading accuracy and fluency. With the non-word reading accuracy, the effect was stronger than the effect of Sight-Word Training [14].

These results suggest that it is important to teach Phonics explicitly to children with dyslexia, because they are able to learn from the Phonics Training better than from the Sight-Word Training. Although both the Sight-Word and the Phonics Trainings had significant effects on word reading fluency and comprehension, the effect of the Phonics Training was higher. It was thus recommended to teach the Phonics rules within the Phonics Training before the Sight-Word Training.

Many other researches have been carried out in other countries, where the official language is nonphonemic as English, or where it is harder to teach children to read and write as the language is not regular [14].

In 2012, Ahmad et al. applied the Phonics Reading Technique and the Multisensory Approach combined with interactive multimedia for dyslexic learners in Malay language. He concluded that using a combination of the above-mentioned approaches was more interesting, attractive and user-friendly for dyslexic learners than the common teaching methods [15].

In 2016, Tilanus, Segers and Verhoeven currently examined the responsiveness to a 12 -week Phonics intervention among 54 Dutch children with dyslexia and compared them to 61 intact learners. The accuracy and efficiency of grapheme-phoneme correspondence, decoding words and pseudo-words as well as the accuracy of spelling before and after the intervention were examined [16].

Results showed that the children with dyslexia were significantly weaker in all reading and spelling 
measures in pretest. During the intervention, the children with dyslexia made more progress on grapheme-phoneme correspondence, (pseudo)word decoding accuracy and efficiency, and spelling accuracy than the intact reading group. Furthermore, the researchers found a direct effect of the precursor measures rapid automatized naming, verbal working memory and phoneme deletion on the dyslexic children's progress in GPC speed, and indirect effects of rapid automatized naming and phoneme deletion on word and pseudo-word efficiency and word decoding accuracy via the scores in pretest [16].

Besides the research studies, there are many commercial Phonics programs providing their methods and instructions on how to teach dyslexic learners English reading and spelling. All the programs have their own copyright, materials, tutors and even online applications. We can find many tutoring demos and testimonials from parents and teachers on their websites. As they are commercial, they generally sell their programs, so you can buy the program and materials or download applications.

For instance, the Barton Reading \& Spelling System, operating since 1998, is a research-based tutoring system for children, teenagers and adults who struggle with spelling, reading and writing due to dyslexia or other learning disability. It was established by Suzan Barton, whose nephew had a learning disability and she wanted to help him as nothing at school worked. In the year 10, her nephew was told, that he was never going to learn how to read, although his IQ was over 130. As Suzan Barton (2016) explains, the Barton Reading \& Spelling System is a simultaneously multisensory structured explicit and systematic Phonics approach teaching learners how to read and spell by sounding out instead of memorizing, showing learners the logic in the language. It has been influenced by Orton- Gillingham's Approach and Methodology and its effectiveness has been proved by fifteen independent studies from public and private schools across America [5].

Another learning program, the Wilson Language Training, that has received the certification from the International Dyslexia Association, is a structured literacy program based on phonological-coding research and the Orton-Gillingham principles [5]. It systematically teaches the structure or the English language and decoding and encoding skills to the level of mastery.

We could go on with other programs, but most of them are based on the same principles. Some of them are even software based, what is great for dyslexic learners, as using technology is one of the adjustments that makes their learning easier. Many programs across English speaking countries incorporate the Orton-Gillingham Approach or similar approach that support phonemic awareness, fluency and strategies for spelling and reading comprehension.

\section{Pilot research}

As the Phonics method is well-known in an English-speaking environment and other countries that have the phonemic type of language, several researchers have applied Phonics in English-speaking classes to study its effectiveness. Nevertheless, there has not been any research that would study the Phonics method for teaching English as a second language. Therefore, we have created the questionnaire where we would ask Slovak teachers of English what methods they use for teaching English reading and spelling, whether they know the Phonics method and if so, whether they use phonetic exercises at the lesson and how often.

In order to find out whether Slovak learners are able to process the phonetic rules, understand them and later apply them in practice, we have conducted the action research with 27 learners in the year 3 of a primary school divided into two classes. There were three integrated learners in each class with a special learning difference as well, mainly dyslexia, but in some cases accompanied by ADHD or dysgraphia.

We had chosen learners in the year 3 , because in this year learners start to practice English spelling and reading more intensively compared to year 1 and 2 , where they generally learn poems, sing songs, and basically build their vocabulary. At most schools, there is one lesson of English as a foreign language per week in year 1 and two lessons of English in year 2. In year 3 there are two or three lessons of English per week depending on the decision of school.

In this case, the Phonics method would serve as a tool for teaching both reading and pronunciation, as learners in non-native environment learn pronunciation through reading as well. Therefore, we consider the terms reading and pronunciation equal in our study. Before carrying out the action research we had observed a class of 26 pupils in an English speaking country, Northern Ireland and later two classes of 14 and 13 pupils in non-English speaking country, Slovakia. We observed the classes for a month in order to find out which techniques were used for teaching English reading and spelling. The observation in Northern Ireland served also as an initial incentive to apply Phonics in Slovak classes.

In the following subchapters we are going to describe methods that were used for teaching English, either as a mother tongue or a foreign language, we are going to give a slight insight how the classrooms looked like as the environment where the pupils learn ought to be stimulating.

\subsection{Observation of a class in Northern Ireland}

Classroom: A combined class of 26 young learners in the year 2 and 3 were taught by a teacher and a teacher's role was supported by a classroom assistant who usually helped learners when they were 
struggling with the tasks. A classroom's walls were full of educational posters, e.g. the cardinal and ordinal numbers, alphabet, the map of the world, pictures of the students. Moreover, there were many materials, such as, whiteboard, books, educational games, jigsaw puzzles, cubes with numbers, scissors, crayons etc. and a corner for monthly projects. Students sat at the tables in the group of 4-6. Between the learners' tables and the teacher's table there was a carpet, where children sat every morning, discussed the attendance or whether they had fulfilled their duties and they read a book a together. The classroom was colourful and stimulating.

Teaching and learning: Learners studied subjects such as Language and Literacy, Mathematics and Numeracy, World around us, The Arts, Physical Education, Religious education and Spanish. Subjects like Language and Literacy and Mathematics were on a daily basis.

Language and Literacy lessons usually started with reading a big-sized book. Students sat on the carpet and a teacher read for the whole class. Before the actual reading, the teacher let the children describe the pictures and guess the story according to them. It was very interesting, because it supported children's imagination, each one come up with their own story and they complemented each other's ideas. Generally, they also contributed with their own experiences which evoked discussion. After this pre-reading part, the teacher started to read the story, stopping on each page giving learners additional comprehension questions. Sometimes, if the teacher came across words that were made of the sounds that children had learnt, she pointed out the word and asked them to read it aloud. In the same way, if they came across the sound they were just learning, they read it together, or she asked individual students to read the word and write it on the board. Further, they moved to writing tasks. Students usually created sentences to sum up the story they had just heard. As students in this year already knew some phonics, they could also write some words and combine them into sentences. There were however, words consisting of sounds that children did not know. In that case, the teacher let them guess how the word, or that sound was written, and she only corrected those words or sounds they had already managed to learn. The teacher did not correct the sounds children had not learnt, so that they did not feel like failing in writing.

Teaching phonics: Teaching phonics was a very complex process. The teacher followed the rules of Northern Irish Curriculum that was created by the Department of Education, Education and Library boards, Education and Training Inspectorate and became statutory in 2009 .

They followed the suggested overview of linguistic phonics. In the overview, there was written which stage needed to be followed in the particular month of the school year and which sounds needed to be introduced each week. The teacher helped herself with the word bank for each stage and used it in the lesson, but it was rather a guide for her and she complemented it with other words that interested or were known to pupils [17].

As a linguistic phonics approach is based on how sounds are presented in print, it is important that account is taken of local dialect, in this case, the Northern Irish dialect.

In the curriculum, there is a suggested procedure of teaching phonics divided into weeks or months. For example, in the observed class, the primary 2 had to follow stages 5 and 6 in the period of two months (March-April) and each week pupils learnt one of the target sounds such as oa as in home, ee as in see, oo as in good, ay as in play, ow as in brown. At the same time, the primary 3 had to learn consonant variations such as se/ce as in December or city, 1/le as in loud or uncle, c/ck as in kick or cat, w/wh as in went or where, $\mathrm{n} / \mathrm{kn}$ spin or knee, v/ve van or given.

At the lessons the teacher encouraged pupils to investigate and discover the words and their spelling or reading. Moreover, the teacher tried to make it entertaining for children, e.g. children voted for the right spelling and the groups or individuals were awarded if they guessed the spelling or reading right.

At the lessons, teacher supported pupils to break words into syllables, hear the individual sounds within words, think about which letters could represent each sound, identify which spelling "looks right", decide and confirm the correct spelling. When they learnt the words, the teacher also asked them to think about ways to remember how to spell these words, e.g. by using mnemonics. However, many times, the right spelling needed drilling and repeated opportunity to practise the particular spelling of the word.

Teaching of reading and spelling happens at the same time. Pupils learn sounds, think of words where sounds can be found, break the words again and try to spell them. However, handwriting is another skill that needs to be taught. The right use of a pen and manipulating of a pen are essential for writing. Therefore, the teacher prepared many activities that involved fine motor skills. For example, the teacher let pupils cut the pieces of paper by themselves instead of pre-cutting the material (although, it would save time at the lesson), because she wanted them to practise their fine motor skills. They were also doing many activities that included folding or manipulating the paper, playing with modelling clay, drawing etc.

\subsection{Observation of classes in Slovakia}

Classroom: Classroom was colourful with many educational posters such as ordinal, cardinal numbers, irregular verbs, animals and almost each object in the classroom was labelled with its English name, such as wall, door, blackboard, crayons etc. Students sat at the tables in two or alone. There were many supporting 
materials such as blackboard, CD player, books, TV Screen, crayons, markers, scissors etc.

Teaching and learning: TPR activities were predominant, for example, when pupils learnt to name activities (e.g. jump, sit down, touch sth.) or parts of the body. At each lesson pupils were doing listening activities followed by writing and speaking activities. In the activity book, pupils did many matching exercises, crosswords or filling in exercises.

Listening: Before listening, the teacher always let the pupils look at the pictures and guess what was going to happen in the text or describe the pictures. When children were guessing they usually answered in Slovak language, because they did not know the words in English yet, but many times they knew at least a word or a phrase in English, they answered in English or the teacher helped them to remind and answer properly in English. Listening usually served as the introduction to the new vocabulary. Pupils listened to the text part by part and repeated what they had heard. In the activities such as "listen and number" or "listen and draw" pupils listened to the text at least twice.

Listening to songs or chants was very popular among children. The rhythm of the song and the rhymes were entertaining and helpful for children, because they learnt the right pronunciation of the words. The recordings of songs or activities were recorded by native speakers, so pupils could listen to the authentic pronunciation.

TPR activities: Many listening activities were accompanied or followed by TPR activities. They listened to the text and acted out what they had heard.

Example: One lesson, pupils were learning phrases such as "take off your shoes, put on your sweater, look into the mirror, put on your mask etc." Firstly, pupils listened to the text, numbered the pictures and then they had to act out the actions. The activity was repeated at least twice, so that the students remembered the phrases

In this case, TPR activity served as a feedback to the teacher whether pupils had understood and learnt the phrases.

Pronunciation and speaking: After pupils understood the meaning of the words, they tried to pronounce the words. Pupils repeated either after the teacher or the listened to text. Speaking was an essential part of the lesson and every time a pupil mispronounced the word, the teacher immediately corrected the pupil and asked them to repeat it after her correctly.

Reading: The most common method used to teach pupils read was "look and say", i.e. look at the word and repeat the right pronunciation of the teacher. When pupils listened to the songs, the teacher asked them to follow the text in the book in order to connect the heard text with the written text. Then pupils were reading aloud together or separately. The teacher stopped the listening part by part and asked students to repeat, but at the same time follow the text in the book. Pupils had to read the text more times in order to learn how to read it correctly.

In the case of misreading, pupils were corrected, but they were not given any rules or suggestions on how is sh or al are read in the word. We have realized that pupils are able to read only the known words, but they are not able to guess the pronunciation of the unknown word.

Writing: The types of writing done at the lesson were mostly controlled and guided. Many times pupils copied the words, phrases or sentences in order to learn to write them properly.

Example: In the activity book there was a followup writing activity to the phrases mentioned above. According to pictures, pupils had to put the sentences into the right order and then copy the sentences and write them to the particular picture.

In another activity they had to put the words into the correct order. It was a type if guided activity, because they had to figure out the word order, but on the other hand, they used the words written in the activity.

However, sometimes they had to create their own sentences after they had learnt the needed vocabulary. These types of activities were free, although pupils could help themselves with the examples prescribed in the book.

Writing usually came as the last skill to be practised. The teacher focused firstly on the right pronunciation and the understanding the meaning and after that they started to practice spelling. Writing of the given words was learnt throughout many different opportunities to write such as writing for homework, writing at the lesson into the notebook or activity book, or collective writing or writing on the blackboard. Drilling was the most typical method for teaching the correct spelling.

In order to learn the vocabulary properly, the words appeared in many different activities many times with little variations.

\subsection{Questionnaire results}

The aim of the initial questionnaire of our pilot research was to find out whether Phonics method is known by the Slovak teachers of English. We were also interested in how often the teachers practice pronunciation activities and what techniques they use in their English lessons. The sample asked was the teachers teaching at the first level of primary schools. Their teaching practice was 7.94 years on average, the longest teaching practice being 37 years and the shortest one being 1 year.

We asked what methods and techniques the Slovak teachers of English use to teach pronunciation. Most of the teachers, 33\%, use the "listen and repeat" technique, $28 \%$ prefer reading aloud, $18 \%$ of the 
asked teachers read poems and songs with learners and $17 \%$ of teachers use visual aids.

We also asked the teachers how often they practise English pronunciation in their lessons. $66 \%$ of the teachers practise pronunciation at each lesson, $14 \%$ practise pronunciation once a week, $14 \%$ only rarely, $4 \%$ never practise pronunciation and $2 \%$ devote their time to pronunciation once a month.

As the Phonics method is quite a new method in our context, teachers were asked if they were aware of the method and if so, whether they applied it in their lessons. $60 \%$ of the teachers asked do not know the Phonics method at all. $40 \%$ of the teachers know the method, but it does not necessarily mean that they apply it in their lessons. From the teachers who know the Phonics method 30\% apply and 35\% do not apply it in their lessons. $28 \%$ of the teachers use the Phonics method only sometimes.

Although there are materials that cover few Phonics instructions available also in Slovakia, they are generally omitted by teachers at the lesson from various reasons, such as insufficient knowledge about how to apply the Phonic rules, or not enough time at the lesson or it can be considered difficult or useless to practice, as pronunciation and spelling is generally taught by constant drill, repetition and practice.

\subsection{Action research results}

We applied Phonics generalizations in two classes with integrated learners with dyslexia and accompanied learning differences for 4 weeks once a week.

We have chosen a few Phonics generalizations to be introduced at the lessons. As pupils in the year 3 already know the letters and are able to write and read in the Slovak language, we skipped the initial stages of Phonics instructions. It would not serve the purpose of the research if we had dealt with the Phonics instructions which have identical phonetic realization in the Slovak language, e.g., mop, peg, dog, bin etc., even the digraphs such as $f l, s p, b l$. Therefore, vowel sounds like $a, e$ (for the comparison of the sounds $a$ and $e$, because they sound similar in Slovak), $u$, digraphs $s h$, $h$ and th and the all ending sounds have been chosen.

The evaluation has been carried out from two points of view, the researcher's and the teacher's. The researcher was leading the Phonics lessons and the teacher was in the role of an observer. Both, the researcher and the teacher have filled in the same evaluation sheet after each lesson. They evaluated the researcher's clarity of presenting the Phonics rules, her pronunciation and accuracy, how pupils coped with the instruction, whether they were able to understand the instructions and complete the tasks and whether they had any additional questions.

The teacher and the researcher have agreed that the Phonics instructions are worth being applied in the lessons, because pupils are able to cope with them and use them in practice, both in writing and reading. It enabled pupils to read not only words they know, but to guess the pronunciation and spelling of the unknown words as well, so our primary concerns about whether it was too complicated and demanding for our learners dissolved. Moreover, we realized that some of the tasks were too easy for the learners, while other made pupils think about the rules. Therefore, it is important to present tasks that are challenging enough and activate learners' metacognitive skills, but on the other hand, they should not be demotivating.

However, it has been remarked, that short Phonics instructions at the beginning of the lesson or in the middle of the lesson would be more beneficial than the whole session of the Phonics instructions as after a while, pupils were losing their concentration and interest in doing basically the same type of tasks. Kralova (2010) emphasizes that pronunciation needs to be practised more often and for a short period of time [18].

Concerning learners with dyslexia and other learning differences, we realized that they too were able to understand the Phonics generalizations, but compared to intact learners, they still made more mistakes in exercises or needed extra guidance in carrying out the exercises. However, the good point is that there was no need to create completely new exercises or accommodate tasks considerably in order to teach the Phonics instructions to integrated learners. Both integrated and intact learners were able to follow the instructions, while integrated learners needed only more time and slower pace alongside multiple opportunities for revision and fixation.

\section{Recommendations and accommodations to referring research}

Thanks to the pilot research we have set up the research design in the form of the case study where we are going to focus on teaching English reading, pronunciation and spelling to learners with special educational needs, dyslexia predominantly, in the inclusive classroom, i.e. altogether with intact learners. We are going to study whether the Phonics method is appropriate for teaching English as a second language to dyslexic learners. There has not been any research that would study the effectiveness of the Phonics method by learners with dyslexia or other learning differences in teaching English as a second language in the longitudinal research. However, according to the research that have been already carried out and according to the characteristics of the Phonics method, the method is applicable for learners of English as a foreign language in the non-native environment and we suppose that the Phonics method will be beneficial for learners with special educational 
needs as well.

All the accommodations are going to be adapted to the needs of integrated learners, because it is supposed that all the adjusted methods or environment changes beneficial for integrated learners are going to be beneficial for intact learners as well.

First of all, we have to focus on the appropriate choice of the Phonics generalizations. We are going to deal with phonemes that have different graphical realization and do not occur in Slovak language or are not even similar to Slovak phonemes. As we have already mentioned, the phonetic rules have to be challenging enough in order to serve the purpose, otherwise learners lose their interest and concentration in learning. Speaking of learners' interest, the types of tasks need to be varied and the time devoted to the exercises and phonetic instructions needs to be shorter and more frequent rather than devoting the whole lesson to teaching the Phonics instructions.

We are also aware of the limitations such as the number of students in the classroom and a combination of intact and integrated learners, different working pace of learners, their age and the behavioral characteristics linked to the age, cognitive or even language barrier, like vocabulary. We understand, that all these factors may influence our research, but we believe, it will bring be new valuable knowledge.

We believe that research will bring more light into teaching dyslexic learners, improve their receptive and productive skills in a foreign language and help teachers lead the lesson in a more logical and systematic way.

\section{Acknowledgements}

This research was funded by the Scientific Grant Agency of the Ministry of Education, Science, Research and Sport of the Slovak Republic (KEGA 006UKF-4/2017).

This paper was presented at the WCSNE-2017 held in Cambridge on 11.-14.12.2017.

\section{References}

[1] U. Frith, "Paradoxes in the definition of dyslexia", Dyslexia, 5, 1999, p p. 192-214.

[2] "Understanding Dyslexia", Lucid research, 2006

[3] J. Nijakowska, J., Kormos, S. Hanusova, B. Jaroszewicz, B. Kálmos, I.Á. Sarkadi, M.A. Smith, E. SzymanskaCzaplak, \& N. Vojtkova, DysTEFL - dyslexia for teachers of English as a foreign language: Trainer's booklet. University of Lodz, Poland, 2013.

[4] E. Schneider, M. Crombie, "Dyslexia and foreign language learning", British Dyslexia Association, London: David Fulton 2003.
[5] B. Gillingham, B. Stillman, Remedial training for children with specific disabilities in reading, writing and penmanship, Educators Publishing, Cambridge, 1960.

[6] "Multisensory structured language teaching", The Interpretation of Cultures, New York, 2016.

[7] W.A.Scott, L.H. Ytreberg, Teaching English to Children: Longman Keys to Language Learning, Longman, Essex, 1994.

[8] P.C. Burns, B.D. Roe, E.P. Ross, Teaching reading in today's elementary schools, 1988.

[9] T. Piper, Language and Learning: The Home and School Years, Merrill Prentice Hall, New Jersey, 2003.

[10] T. Nicholson, "Do children read words better in context or in lists?", Journal of Educational Psychology,1991, pp. $444-450$.

[11] D.G. HISKES, Phonics pathways: clear steps to easy reading and perfect spelling. Jossey-Bass, a Wiley imprint, San Francisco, 2011.

[12] J.A. BOWEY, "Need for systematic synthetic phonics teaching within the early reading curriculum", Australian Psychologist, 2006.

[13] What are specific learning difficulties? The British Dyslexia Association. 2016, Available at: http://www.bdadyslexia.org.uk/educator/what-are-specificlearning-difficulties\#A.D.H.D/A.D.D.

[14] G. McArthur, A. Castles, S. Kohnen, L. Larsen, K. Jones, T. Anandakumar, E. Banales, "Sight word and phonics training in children with dyslexia" Journal of Learning Disabilities, 2015.

[15] S.Z. Ahmad, H.M. Ekhsan, A.F. Rosmani , M.H. Ismail, Applying phonic reading technique and multisensory approach with interactive multimedia for dyslexia children, "Humanities, Science and Engineering (CHUSER)”, Malaysia, 2012.

[16] Tilanus, E. A. T., Segers, E., \& Verhoeven, L. (2016). Responsiveness to Intervention in Children with Dyslexia. Dyslexia, 22: 214-232. doi:10.1002/dys.1533.

[17] Linguistic Phonics: Suggested Line of Progression and Word Bank for Primary Schools [online], 2009, Available at: http://www.seelb.org.uk.

[18] Z. Král'ová, Kvalitatívna aproximácia v systéme slovenských a anglických krátkych vokálov, ÚJEP, Ústí nad Labem, 2010. 